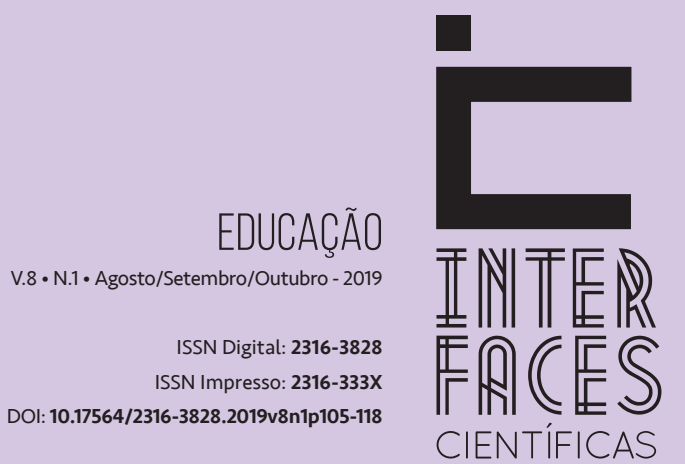

\section{PLANEJAMENTO EDUCACIONAL:} UM OLHAR NO PLANO ESTADUAL DE EDUCAÇ̃̃̃ DE ALAGOAS

Inalda Maria dos Santos ${ }^{1}$ Jacy de Araújo Azevedo ${ }^{2}$

\section{RESUMO}

0 presente artigo objetiva analisar o planejamento educacional no contexto do Plano Estadual de Alagoas. Para tanto, está organizado, para além da introdução e das considerações finais, em três seções. A primeira apresenta uma reflexão acerca da trajetória do planejamento educacional no contexto brasileiro; a segunda, discute o planejamento educacional a partir da década de 1990; e a terceira atém-se ao planejamento de Alagoas (2015-2025). Utilizamos enquanto metodologia, a revisão de literatura e a análise documental, tendo como principais fontes de pesquisa os trabalhos de Azevedo (2015), Saviani (2014), Azanha (2004), Baía Horta (1991), e os documentos oficiais tais como, o Plano Nacional de Educação, o Plano Estadual de Educação, a Lei de Diretrizes e Bases da Educação, entre outros. Concluímos, apontando para a necessidade de ter o planejamento educacional como elemento preponderante de mudança no cenário educacional, sobretudo no cumprimento das metas em tempo hábil. Este estudo aponta que em Alagoas, as metas que teriam que ser cumpridas em 2016 não foram alcançadas, trazendo assim, um prejuízo para o cenário educacional alagoano.

\section{PALAVRAS-CHAVE}

Planejamento Educacional. Plano Estadual. Plano Nacional. 


\section{ABSTRACT}

The present article aims to analyze educational planning in the context of the State Plan of Alagoas. For this, it is organized, in addition to the introduction and the final considerations, in three sections. The first presents a reflection about the trajectory of educational planning in the Brazilian context; the second, discusses educational planning from the 1990s; and the third is in Alagoas planning (2015-2025). We use as methodology, literature review, and documentary analysis, having as main sources of research the works of Azevedo (2015), Saviani (2014), Azanha (2004), Baía Horta (1991), and official documents such as, the National Plan of Education, the State Plan of Education, the Law of Guidelines and Bases of Education, among others. We conclude by pointing to the need to have educational planning as a preponderant element of change in the educational scenario, especially in meeting the goals in a timely manner. This study indicates that in Alagoas, the goals that would have to be met in 2016 were not reached, thus bringing about a loss to the Alagoan educational scenario.

\section{KEYWORDS}

Educational Planning. State Plan. National Plan

\section{RESUMEN}

El presente artículo tiene como objetivo analizar la planificación educativa en el contexto del Plan Estadual de Alagoas. Para ello, está organizado, además de la introducción y de las consideraciones finales, en tres secciones. La primera presenta una reflexión acerca de la trayectoria de la planificación educativa en el contexto brasileño; la segunda, discute la planificación educativa a partir de la década de 1990; y la tercera se atiene a la planificación de Alagoas (2015-2025). En el presente trabajo se analizaron los resultados obtenidos en el análisis del Plan Nacional de Educación, Plan Estatal de Educación la Ley de Directrices y Bases de la Educación, entre otros. Concluimos, apuntando a la necesidad de tener la planificación educativa como elemento preponderante de cambio en el escenario educativo, sobre todo en el cumplimiento de las metas en tiempo hábil. Este estudio apunta que en Alagoas, las metas que tendrían que ser cumplidas en 2016 no fueron alcanzadas, trayendo así, un perjuicio para el escenario educativo de Alagoas.

\section{PALABRAS CLAVE}

Planificación Educativa. Plan Estatal. Plan Nacional 


\section{INTRODUÇãO}

O Plano Nacional de Educação (PNE) se constitui um instrumento de planejamento educacional no contexto das políticas públicas educacionais do Brasil, sendo o mesmo objeto de várias batalhas históricas no decorrer dos anos, desde o movimento dos pioneiros (1932) até os dias atuais.

Um plano de educação deve se definir como um conjunto de medidas de natureza técnica, administrativa e financeira - a serem executadas a partir de uma política educacional. Esse conceito de plano tem a sua principal vantagem no fato de pôr em relevo o que é realmente imprescindível: a definição de uma política educacional. (AZANHA, 2004, p. 351).

Ao tratar sobre a política pública educacional, Azevedo (2003, p. 38) diz que "política pública é tudo o que um governo faz e deixa de fazer, com todos os impactos de suas ações e de suas omissões" As políticas educacionais surgem do Estado, como qualquer outra política pública. Elas orientam e regulam o campo educacional. Nesse sentido, os planos de educação são construções no âmbito das políticas públicas educacionais.

Os planos de educação estaduais e municipais se originam dos Planos Nacional de Educação (PNE). No PNE, Lei no 10.172 de 9 de janeiro de 2001, prevê a elaboração de Planos Estaduais e Planos Municipais de Educação, respectivamente pelos Estados e Municípios, para dar suporte ao cumprimento das metas nacionais. Estes planos devem ser debatidos e elaborados pela sociedade civil e governo para não se tornarem meros planos de gabinete.

A discussão sobre os planos educacionais tem se ampliado e se fortalecido pela necessidade de por meio dele, garantir o direito à educação básica com qualidade, diminuição das desigualdades sociais e a valorização dos profissionais da educação. E nesse sentido, o estudo sobre o Plano Estadual de Educação de Alagoas (PEE/Al) se justifica por Alagoas possuir um dos piores indicadores educacionais do país.

Ao trazer uma análise sobre a temática do planejamento educacional com foco no PEE, nos ancoramos na pesquisa qualitativa, tendo como base a revisão de literatura e análise documental, tendo em vista o Plano possuir metas que deveriam ser cumpridas em 2016.

Este artigo tem como objetivo refletir sobre o planejamento educacional enquanto política pública; ele no primeiro momento traz um breve percurso histórico do planejamento no contexto nacional; no segundo, discute o planejamento educacional a partir da década de 1990; e no terceiro, analisa o Plano Estadual de Educação (2015-2025). Concluímos então, que o planejamento educacional precisa ser garantido tanto na sua elaboração, quanto na sua execução e monitoramento para que ele tenha efetividade.

\section{UM BREVE PERCURSO HISTÓRICO DO PLANEJEMENTO EDUCACIONAL.}

Ao tratar sobre planejamento educacional, Freitas (2003) afirma em seus estudos que o ato de planejar é inerente à história. 
Se tratando de Planejamento Educacional, Bordenave e Pereira (2005, p. 71) dizem que [...] é o processo de abordagem racional e científica dos problemas de educação, incluindo definição de prioridades e levando em conta a relação entre os diversos níveis do contexto educacional". O Planejamento Educacional se constitui um instrumento importante de organização de ações educacionais, sendo desta forma, um direcionamento definido por meio de diretrizes organizados pelas políticas educacionais, estruturando assim, por meio de Planos Nacionais.

Ao fazer a discussão acerca do planejamento educacional, Baia Horta (1997, p. 195) diz que "o planejamento educacional constitui uma forma específica de intervenção do Estado em educação, que se relaciona, de diferentes maneiras, historicamente condicionadas, com as outras formas de intervenção do Estado em educação[...]"

Paiva (2009) traz uma reflexão acerca da relação entre o planejamento e o projeto de educação enquanto representações de um projeto de sociedade. 0 planejamento educacional não está desvinculado de um projeto societal, e nesse sentido, para a autora, a concepção de planejar educação parte deste projeto.

Nas décadas de 1950 e 1960 cuja tônica estava voltada para o economicismo e o desenvolvimentismo do país, o planejamento educacional seguia essa lógica, pois a educação era considerada uma ferramenta importante para que o país se tornasse um país desenvolvido. Na década de 1970, nos domínios da ditadura militar, o planejamento torna-se mais voltado para a tecno-burocracia, o que é perceptível pela forma como foi tratado o Plano Nacional nesse contexto, sendo reduzido a ser plurianual de financiamento e orçamento, se esvaziando do seu sentido político. Segundo Shiroma (2011), a teoria do capital humano torna-se central no planejamento educacional nas décadas da Ditadura Militar.

É a partir da década de 1990, com a reforma do Estado que é incorporado ao planejamento educacional uma série de documentos regulatórios provenientes da União, cujo foco seria a descentralização e democratização das instâncias dos sistemas escolares. Mesmo com a criação do PNE (2001-2010), o qual dividiu espaço com vários planos entre eles o Plano de Ações Articuladas (PAR) e o Plano de Desenvolvimento da Educação (PDE), os quais não mantiam um diálogo com o PNE.

Azevedo (2015, p. 266), tratando sobre planejamento diz que "O planejamento governamental de uma dada sociedade é composto da planificação do conjunto dos setores que a compõem, a exemplo do setor (ou campo) da educação, sendo os planos, programas e projetos a materialização dessa planificação".

$\mathrm{Na}$ concepção de Castro(2010), um plano se constitui um documento que concretiza o planejamento a partir da análise da realidade, buscando transformá-la com criação de metas. Em relação a criação das metas, Castro (2010) e Dourado (2011) dizem que essas metas no contexto de um plano e na criação do planejamento se caracterizam por estabelecer interesses de grupos hegemônicos.

0 ideário de um plano que de fato pudesse servir de planejamento educacional surge no movimento da Escola Nova em 1932. As primeiras ideias de um Plano para a educação, abrangendo todo o território nacional, tiveram origem no Manifesto dos Pioneiros da Educação, lançado em 1932, por 26 (vinte e seis) intelectuais brasileiros. Para Saviani, a ideia do Plano no contexto dos Pioneiros seria "entendida como um instrumento de racionalidade científica no campo da educação em consonância com o ideário escolanovista” (SAVIANI, 2010, p. 75). 
A luta do Manifesto dos Pioneiros era que a escola fosse pública, gratuita e laíca. 0 objetivo do Manifesto era oferecer diretrizes para uma política educacional. 0 documento apresentou simultaneamente um delineamento de ações a nível nacional, em busca da estruturação de um sistema educacional e um documento de discussão e reflexão sobre o ambiente político e social dos anos de 1920 e 1930.

Esse movimento deixou como saldo positivo a inclusão do artigo 150 da Constituição Brasileira de 1934, que estabeleceu como competência da União, fixar o estabelecimento de um Plano Nacional da Educação, bem como coordenar e fiscalizar sua realização no País.

O Conselho Federal de Educação (CFE) é criado por meio do Decreto 19850/1931 cuja missão a partir da Constituição de 1934, foi prescrito no Art. 152 - "Compete precipuamente ao Conselho Nacional de Educação, organizado na forma da lei, elaborar o plano nacional de educação para ser aprovado pelo Poder Legislativo".

Ao ser organizado esse Plano de Educação Nacional em 1937 “a promulgação de uma lei geral de ensino, ou seja, de um Código da Educação Nacional, apresentava-se como condição prévia para a elaboração de um plano de educação" (HORTA, 1997, p. 149-150). Encaminhado à Câmara dos Deputados, o referido plano não chegou a ser aprovado (SAVIANI, 2010).

Entretanto, a elaboração da primeira Lei da Educação de $n^{0}$ 4024/1961, tramitou no Congresso Nacional de 1948 até 1961, e após esse longo tempo não apresentou em nenhum momento no seu bojo referência sobre a elaboração de um plano e/ou um planejamento educacional. Não havia ações efetivas para tratar de problemas educacionais da época como o gritante número de analfabetos existentes na nação. Nesta Lei, o planejamento se traduz em organizar e aprovar orçamentos para o ano subsequentes.

Pela importância da Lei da Educação de nº 4024/1961, em 1962 foi criado o primeiro Plano Nacional de Educação, com vigência de oito anos. Sua organização se pautava em metas qualitativas e quantitativas, limitando-se a dirigir os projetos e os recursos ligados ao Ministério da Educação.

Baia Horta (1997, p. 169), analisa a influência da lógica econômica voltada para o desenvolvimentismo no contexto dos planos educacionais afirmando que:

Os planos educacionais do regime militar até 1974, afastando-se, no setor Educação, da opção político-social de abrir o sistema educacional ao maior número possível de educandos, determinada pela Lei de Diretrizes e Bases e adotada no documento do Conselho Federal de Educação e no Plano Trienal, assumiram em maior ou menor grau, um estilo economicista de situar a Educação no processo de desenvolvimento. Em todos os planos os setores sociais, inclusive o da Educação, são considerados em termos de suas consequências econômicas.

Ao ser reformulada a Lei de Diretrizes e Bases da Educação Nacional (Lei 5692/1971), não deixa claro quais são os objetivos para tratar com os problemas educacionais vigentes, ficando o planejamento educacional sem projeção naquele contexto. 


\section{PLANEJAMENTO EDUCACIONAL A PARTIR DA DÉCADA DE 1990.}

O Brasil, no período de Fernando Henrique Cardoso (1995 a 1998 e 1999 a 2002) passou por diversas transformações na administração pública. Estas mudanças se pautariam em uma reestruturação interna no aparelho administrativo do Estado. Em 1995 foi criado o Plano Diretor da Reforma do Aparelho do Estado (PDRAE), com um desenho de conjunto de mudanças de ordem social, econômica e política, econômica, pautado no diagnóstico de que o Estado estava em crise e que seria necessário diminuir o seu papel no tocante às políticas sociais, buscando desta maneira racionalizar os recursos.

Nessta perspectiva, a educação passa a ser considerada fator fundamental, visto que os sistemas de ensino deveriam ser organizados sob uma nova direção dos marcos normativos. As reformas educacionais se fortalecem por meio das diretrizes educacionais, desde a Constituição Federal (CF) da República Federativa do Brasil de 1988, passando pela promulgação da Lei de Diretrizes e Bases (LDB) 9.394/96 e o estabelecimento do Plano Nacional de Educação (PNE) de 2001.

Para atender as demandas apontadas pela reforma do Estado, foi aprovada em 1996 a nova Lei de Diretrizes e Bases da Educação Nacional (LDBEN 9394/1996), a qual passa a ser vista como principal documento regulatório da educação brasileira nos anos de 1990 no contexto da reforma do estado brasileiro. Constituiu-se como uma legislação reguladora sendo prescritiva, pois se volta à própria práxis da educação.

Acerca da temática planejamento educacional, a obrigatoriedade do estabelecimento do Plano Nacional da Educação (PNE) foi instituída na Constituição de 1988 em seu artigo 214 que diz: "A lei estabelecerá o plano nacional de educação, de duração plurianual, visando à articulação e ao desenvolvimento do ensino em seus diversos níveis e à integração das ações do Poder Público.".

No que refere ao Plano Nacional de Educação, a Lei (9394/1996) trata do assunto em seus artigos $9^{\circ}$ e 87 :

Art. $9^{\circ}$ - A União incumbir-se á de:

I - elaborar o Plano Nacional de Educação, em colaboração com os Estados, o distrito Federal e os Municípios; [...]

[...]

Art. 87 - É instituída a Década da Educação, a iniciar-se um ano a partir da publicação desta lei:

$\S 1^{0}$ - A União, no prazo de um ano, a partir da publicação desta Lei, encaminhará ao Congresso Nacional o Plano Nacional de Educação, diretrizes e metas para os dez anos seguintes, em sintonia com a Declaração Mundial sobre Educação para Todos. (BRASIL, LDB,1996).

Entende-se então, que implantação do PNE, não só passa a ser uma obrigatoriedade por força da lei, mas também passa a ter seus desdobramentos por meio do regime de colaboração entre os estados, municípios e distrito federal.

Para França (2014, p. 3), 
0 regime de colaboração refere-se à forma cooperativa, colaborativa e não competitiva de gestão estabelecida entre os entes federados (União, Estados, Distrito Federal e Municípios), visando ao equilíbrio do desenvolvimento e do bem-estar em âmbito nacional, de forma geral, e na educação, de forma particular.

O Plano Nacional de Educação (2001-2011) enquanto política de planejamento, tinha como tônica principal o fortalecimento da Escola Pública e a democratização da gestão educacional e a universalização da Educação Básica; ele oferecia uma proposta de educação baseada na igualdade e justiça social. O Plano foi enviado à Câmara dos Deputados em fevereiro de 1998, sendo estabelecido como Projeto de Lei de $n^{0} 4.155 / 1998$. O Projeto de Lei do PNE sofreu nove vetos presidenciais, sendo quatro vetos nas metas relativas ao Ensino Superior, uma nas metas relativa à valorização do magistério da Educação Básica, três relacionadas ao financiamento da Educação e uma concernente a Educação Infantil.

Para Saviani (2003), o PNE perde sua função de Plano por ter sofrido nove vetos, que na concepção do autor, inviabilizou a execução do mesmo, como é o caso dos vetos na área do financiamento. $O$ Plano se tornou um documento inoperante, cheios de metas que nunca foram cumpridas. $E$ teve como agravante a transição de governo um ano após ter sido sancionado, o qual privilegiou outras formas de planejamento educacional, criando um plano com um foco gerencialista que foi o Plano de Desenvolvimento da Educação (PDE) em 2007.

Ocorreu no período de vigência do Plano um protagonismo do governo federal frente aos entes federados, na formulação, na implementação e na introdução de políticas, programas e ações relacionadas que, em sua maioria, contribuíram para o cumprimento parcial das metas do PNE, ainda que esse Plano não tenha sido o eixo de ações desencadeadas. (DOURADO, 2011, p. 51).

O PNE sancionado em 2001 teve o seu prazo de vigência em 2010. Sabe-se que este PNE não contribuiu efetivamente para uma mudança significativa na política e no planejamento educacional, entretanto serviu para reflexão acerca dos entraves que produziram a sua ineficácia.

No final do prazo da vigência, ocorreram várias mobilizações para a elaboração do novo Plano, cujo objetivo seria elaborar um novo PNE que de fato se efetivasse enquanto um documento que pudesse ser executado, suplantando os equívocos e as fragilidades apresentadas no PNE anterior.

Após quatro anos de várias conferências municipais e estaduais, seminários, e diversos debates foram realizados e em 2010 o MEC realizou a Conferência Nacional de Educação (CONAE). Uma das principais preocupações era estabelecer o financiamento da educação através do Produto Bruto Interno (PIB) para evitar os vetos que ocorreram no antigo Plano. Depois de um longo percurso foi aprovado o documento final na Lei n⿳013.005, de 25 de junho de 2014, tendo o novo PNE à vigência de 2014 a 2024.

Para Azevedo (2015, p. 266):

O largo período de sua tramitação também pode ser o exemplo dos múltiplos e contraditórios interesses em disputa que constituíram o campo de forças pelo qual o Projeto de 
Lei tramitou. Esse movimento sugere o grau de importância atribuído ao PNE, certamente o principal instrumento das políticas educativas para o próximo decênio, o que nos leva a indagar a respeito da utilidade de um plano.

Enquanto planejamento educacional, o novo PNE (2014-2024), traça 20 metas e 170 estratégias, reduzindo significativamente as metas constante no plano anterior. As metas são para: 1.Educação Infantil, 2. Ensino Fundamental, 3. Ensino Médio, 4. Educação Especial/Inclusiva, 5. Alfabetização, 6. Educação integral, 7. Aprendizado adequado na idade certa, 8. Escolaridade média, 9. Alfabetização e alfabetismo de jovens e adultos, 10. Educação de Jovens e Adultos integrada à Educação Profissional, 11. Educação Profissional, 12. Educação Superior, 13. Titulação de professores da Educação Superior, 14. Pós-graduação, 15. Formação de professores, 16. Formação continuada e pós-graduação de professores, 17. Valorização do professor, 18. Plano de carreira docente, 19. Gestão democrática, 20. Financiamento da Educação.

De acordo com Saviani (2014), este PNE apresenta metas e estratégias mais coerentes e próximas da realidade educacional brasileira. Entretanto o pesquisador diz que o Plano não foi elaborado a partir de um diagnóstico do plano anterior.

O PNE (2014-2024) é aprovado com uma série de desafios, dentre eles a meta que trata do financiamento "Meta 20: Ampliar o investimento público em Educação pública de forma a atingir, no mínimo, o patamar de $7 \%$ do Produto Interno Bruto (PIB) do País no $5^{\circ}$ ano de vigência desta Lei e, no mínimo, o equivalente a $10 \%$ do PIB ao final do decênio" (BRASIL, 2014, p.5). Contempla ações para os níveis de ensino e suas modalidades. Enquanto planejamento educacional, traz uma em sua organização a criação de mecanismos de avaliação e acompanhamento, difenciando este do anterior.

\section{PLANEJAMENTO EDUCACIONAL EM ALAGOAS [2015-2015]}

Seguindo as exigências da CF (1988) e da LDB (9394/96), os estados e municípios deveriam construir os seus planos. Alagoas em cumprimento a exigência da construção do Plano, no ano de 2005, reuniu o Conselho Estadual de Educação de Alagoas (CEE/AL), o Sindicato dos Trabalhadores em Educação de Alagoas (SINTEAL), o Fórum Alagoano de Educação de Jovens e Adultos (FAEJA), o Fórum Alagoano em Defesa da Educação Infantil (FADEI), o Programa de Assessoramento Técnico Pedagógico aos Municípios Alagoanos (PROMUAL/CEDU/UFAL) e outras entidades e organizações ligadas à educação, para elaborar o PEE/AL. O Plano foi aprovado no dia 28 de junho de 2006 na Lei $n^{0} 6.757$ (PEE, 2006-2015)

Nessa direção, como cumprimento da lei federal, ou seja, por força legal, o sistema educacional de Alagoas deveria construir o seu primeiro Plano Estadual de Educação com vigência de 2006 a 2015, com uma ampla participação social, do Conselho Estadual de Educação (CEE/AL), com os Secretários Estaduais de Educação e que, com a Secretaria Executiva de Educação (SEE/AL), e instituir um o Comitê Gestor, tendo este se organizado em Sub- Comitês Temáticos. 
Em concordância com o PNE (2001-2010), o PEE/AL 2006-2015, estabeleceu objetivos e metas para o decênio, bem como as diretrizes político-pedagógicas, considerando todos os níveis e modalidades da educação. De fato, foi o primeiro Plano de Educação construído em Alagoas e com ampla participação social.

$\mathrm{Na}$ apresentação do Plano, o comitê gestor trata a sua construção como um processo participativo e aponta a sua relevância enquanto planejamento educacional a partir da realidade local, ora visto Alagoas ter um dos maiores índices de analfabetismo, de mortalidade infantil, de desemprego, de pobreza do Brasil.

O PEE/AL (2006-2015, p. 9) traz a sua concepção de planejamento, afirmando que "[...] planejamento aqui deve ser entendido tanto como antecipação, quanto como proposição e/ou redirecionamento das ações, sempre como espaço de participação social.

Tanto no sentido da antecipação, elaboração e no redirecionamento do Plano, a participação social se configura como experiência democrática de participação cujo objetivo é a melhoria da qualidade da educação. 0 contributo dessa participação se fortalece porque os atores sociais têm papel determinante na leitura da realidade e nas propostas que nascem do contexto social do qual estão inseridos, colaborando para construção de políticas públicas que contribuam para o desenvolvimento e fortalecimento da educação.

O próprio documento do PEE/AL (2006-2015), tendo em vista a significância do Plano, afirma:

[...] trata-se de um plano de ESTADO, e não de Governos - sejam eles Estadual ou Municipais. Ele ultrapassa dois períodos governamentais, sendo a sociedade toda a beneficiária de suas ações e guardiã de seus compromissos. Mesmo mudando o governo e alternando-se partidos no poder, o Plano deve continuar, até porque ele atende a ditames constitucionais e legais que o preconizam para uma década. (ALAGOAS, PEE/AL 2006-2015, p. 12).

Ao colocar o PEE/AL como um plano de Estado, assume que não está limitado a um governo, mas perpassa por vários, sendo a sua dinâmica envolver várias esferas da máquina estatal, como também estudos técnicos, análises econômicas e os impactos que poderão causar.

Infelizmente o PEE/AL não foi levado em consideração no cenário educacional de Alagoas, ficando um planejamento sem efetividade no Estado. Segundo Consuelo Ferreira, ao tratar sobre os desafios para uma construção da educação pública e de qualidade em Alagoas na década de 2010, no Fórum Nacional dos Conselhos Estaduais de Educação e Distrito Federal (FNCE), a falta de financiamento foi um fator preponderante para que esse Plano não se materializasse como deveria.

Apesar da implantação do Fundo Nacional de Desenvolvimento da Educação Básica (FUNDEB) em 2007, em substituição ao Fundo Nacional de Desenvolvimento do Ensino Fundamental (FUNFEF), a Educação Básica em Alagoas não avançou. Ela conclui que além do financiamento, faltou também a valorização dos profissionais da educação, compromisso com a qualidade social da educação, bem como a efetivação da gestão democrática.

Ao termino de vigência do primeiro plano, é elaborado o segundo PEE/AL (2015-2025), seguindo o que preconiza o PNE (2014-2024) o qual estabelece no $\S 2^{\circ} 4$ do art. $8^{\circ}$ do PNE, que deverá ser elaborado por meio de consultas públicas para a validação do PEE, sendo encaminhado à Assembleia Legislativa. 
O processo de adequação do Plano Estadual de Educação (PEE) foi iniciado com o Fórum Estadual Permanente de Educação do Estado de Alagoas (Fepeal) realizando quatro audiências públicas para a discussão da Lei nº 6757/2006, PEE 2006-2015, com o objetivo de avaliar a lei a partir das experiências dos educadores, estudantes, responsáveis pelos estudantes, gestores e toda a sociedade. Para elaboração do novo PEE, a Secretaria de Estado da Educação - SEE publicou a portaria nº 1.215/20153, em 17 de março de 2015, que designa em seu artigo $1^{\circ}$ o Fórum Estadual Permanente de Educação de Alagoas (Fepeal) para coordenar o processo e institui, em seu artigo $2^{\circ}$, uma comissão técnica de elaboração da proposta de documento base do PEE. (ALAGOAS, PEE/AI 2015-2025, p. 10).

O PEE/AL 2015-2025 é organizados em três capítulos: 1) Diagnóstico da realidade educacional de Alagoas no período de 2009 a 2013, evidenciando os níveis, etapas, modalidades e diversidade educacionais, a formação e valorização dos profissionais da educação, a gestão e financiamento da educação; 2) Metas e Estratégias do PEE em consonância com o Plano Nacional de Educação; e Acompanhamento e monitoramento do Plano Estadual de Educação.

Em relação as metas do PEE/Al, se matem $100 \%$ idênticas ao PNE. O que nos chama atenção são as meta 1 e 3 que preservam o ano de 2016 para a universalização tanto da educação infantil, quanto para o ensino médio, ora visto que no nacional tem-se o prazo de dois anos para a universalização, enquanto que no PEE/Al é apenas de um ano. Prazo este, que consideramos curtíssimo pelos grandes desafios que o próprio PEE apresenta.

Meta 1: universalizar, até 2016, a educação infantil na pré-escola para as crianças de 4 (quatro) a 5 (cinco) anos de idade e ampliar a oferta de educação infantil em creches de forma a atender, no mínimo, 50\% (cinquenta por cento) das crianças de até 3 (três) anos até o nono ano da vigência deste PEE.

[...]

Meta 3: universalizar, até 2016, o atendimento escolar para toda a população de 15 (quinze) a 17 (dezessete) anos e elevar, até o final do período de vigência deste PNE, a taxa líquida de matrículas no ensino médio para $85 \%$ (oitenta e cinco por cento). (PEE/Al 20152025, p. 100; 104).

A Secretaria de Educação em nota à imprensa em relação à meta 1 diz que “[...] essa meta é de responsabilidade dos municípios e apresenta vários problemas para ser atingida em virtude, principalmente, do baixo financiamento para expansão da rede física para atendimento da Educação Infantil (GAZETA WEB, 2017).

Em 2015, havia 75.495 alunos de 4 a 5 anos matriculados na pré-escola, ou seja 83,3\% das crianças matriculadas. A distribuição das escolas de Educação Infantil por dependência administrativa com se configurou assim: as escolas privadas e particulares eram 443, alcançando $21,8 \%$ dos alunos da pré-escola; já as públicas eram 1.593 escolas, equivalendo $78,2 \%$. No ano de 2016 , o qual deveria cumprir a meta da universalização da pré-escola, o quantitativo de públicas diminuíram para 1.557 (76,6\%), já as escolas particulares aumentaram para $476(23,4 \%)$. Fica evidente que a meta não foi alcançada. 
De acordo com os dados do acompanhamento dos planos, a meta 3 que trata do ensino médio, mostra que a porcentagem de jovens de 15 a 17 anos na escola, no quesito da taxa de atendimento, a situação das matriculas do ensino médio em 2015 em Alagoas quando o Plano foi elaborado e aprovado era de 159.825 , ou seja, $84,3 \%$ da população nessa faixa etária. A taxa porcentagem de jovens de 15 a 17 anos matriculados no Ensino Médio - Taxa líquida de matrícula, correspondia a 42,4\%, ou seja, um total de 78.653 (IBGE/PNAD, 2015).

Ao analisarmos os indicadores de 2016, ano que deveria se universalizar o atendimento escolar população de 15 (quinze) a 17 (dezessete) anos, não se atingiu essa meta como previsto no Plano, pois a matrícula no ensino médio não ultrapassou 85\% (IBGE/PNAD, 2016).

Apesar do avanço nas matriculas do Ensino Médio em 2016, ainda não foi suficiente para universalizar com estabelece a meta 3.0 grande desafio é que pelo menos até o termino da vigência deste plano, se consiga atingir esta meta.

Esse PEE/Al não traz no seu texto-base nenhuma referência sobre a concepção de Planejamento Educacional como no primeiro PEE e nem trata sobre as concepções que norteiam a sua construção. Se detêm apenas em fazer um diagnóstico da realidade sem fazer em nenhum momento alusão ao primeiro plano. Faz referência a avaliação e monitoramento por meio de um regime de colaboração com os municípios tendo como base os indicadores educacionais, sem mencionar de que forma será realizada a avaliação e o monitoramento.

Um dos grandes desafios para a educação alagoana é buscar manter este plano vivo e dinâmico, tendo em vista os demais planos não passarem de um compendio de papéis sem grande efetividade no planejamento educacional brasileiro, ora visto que o Brasil, em sua organização política, cria uma série de programas e planos que suplantam os Planos de Educação.

Necessário se faz, compreender a importância de um planejamento educacional voltado de fato para a real necessidade, daí a importância de se monitorar e avaliar estes planos.

\section{CONSIDERAÇÕES FINAIS}

A busca pela efetividade de um planejamento se tornou o foco na prioridade das políticas públicas educacionais nas últimas décadas. Em decorrência das demandas educacionais, surge o planejamento como um importante mecanismo de organização e direcionamento das ações educacionais. Nesse sentido, o planejamento educacional no seu percurso histórico, evidencia que há o reconhecimento de sua necessidade, entretanto, não se deu prioridade e a devida importância na elaboração e execução dele.

É a partir do primeiro PEE/Al (2001- 2010) que o planejamento da educação em Alagoas tomou um novo rumo, embora a sua execução tenha tido pouca efetividade por falta de condições adequadas para o seu cumprimento, sobretudo na área financeira. Temos então, um novo plano (2015-2025), o qual está em andamento e com perspectivas de metas mais exequíveis, embora algumas metas que eram para serem alcançadas em 2016 não foram. Entretanto, a perspectiva é que de forma geral as metas sejam cumpridas até o prazo da sua vigência. 
O planejamento da educação, principalmente no âmbito estadual é de grande importância no processo de organização do sistema estadual de educação de Alagoas, por ser um instrumento para organizar a educação, e pensar ações que de fato venham traduzir as reais necessidades, contribuíndo assim, para a superação dos baixos indicadores que este sistema apresenta.

\section{REFERÊNCIAS}

ALAGOAS. Plano Estadual de Educação (PEE) 2006-2015. Aprovado em 2005. Lei n. 6.757, de agosto de 2006.

ALAGOAS. Plano Estadual de Educação 2015-2025. Maceió: Secretaria Estadual de Educação, 2015.

AZANHA, M. P. José. A política de educação do estado de São Paulo. (Uma Notícia). Considerações sobre a Política de Educação do Estado de São Paulo. In: Educação e Pesquisa, São Paulo, v. 30, n. 2, p. 349-361, maio/ago. 2004.

AZEVEDO, Janete Maria Lins. Plano Nacional de Educação e planejamento: A questão da qualidade da educação básica. Retratos da Escola, v. 8, n. 15, p. 265-280, 2015.

AZEVEDO, Sérgio de. Políticas públicas: discutindo modelos e alguns problemas de implementação. In: SANTOS JÚNIOR, Orlando A. dos et al. Políticas públicas e gestão local: programa interdisciplinar de capacitação de conselheiros municipais. Rio de Janeiro: FASE, 2003

BORDENAVE, Diaz Ruan; PEREIRA, Martins Adair. Estratégias de ensino aprendizagem. 26. ed. Petrópolis: Vozes, 2005. p.71-132.

BRASIL. Constituição (1934) Constituição da República dos Estados Unidos do Brasil. Rio de Janeiro, 1934. Disponível em: http://www.planalto.gov.br/ccivil_03/Constituicao/ Constitui\%C3\%A7ao34.htm. Acesso em: 24 out.2017.

BRASIL. Lei de Diretrizes e Bases da Educação Nacional. Lei número 9394, 20 de dezembro de 1996.

BRASIL. Lei no 13.005, de 25 de junho de 2014. Aprova o Plano Nacional de Educação - PNE e dá outras providências. Diário Oficial da União, 26 jun. 2014. Brasília: Imprensa Nacional. 2014.

BRASIL. IBGE. Notas metodológicas. pesquisa nacional por amostra de domicílios - PNAD.

Volume 1. Brasil. Rio de Janeiro: IBGE, 2016. 
CASTRO, Alda Maria Duarte Araújo. Planejamento educacional. In: Dicionário de trabalho, profissão e condição docente. Belo Horizonte: UFMG/ Faculdade de Educação, 2010, v. 1.

\section{CORREIA, Maria Consuelo. os desafios para a construção da educação pública de qualidade}

em Alagoas. Disponível em: http://fncee.com.br/wp-content/uploads/2015/06/Desafios-para-aConsstrucao-da-Educacao-Publica-de-Qualidade-em-Alagoas-Consuelo.ppsx. Acesso em: 20 out. 2017

DOURADO, Luiz Fernandes. Plano Nacional de Educação como política de Estado: antecedentes históricos, avaliação e perspectivas. In: DOURADO, Luiz Fernandes (Org.). Plano Nacional de educação (2011-2020): avaliação e perspectivas. Goiânia: Editora UFG; Belo Horizonte: Autêntica Editora, 2011.

FRANÇA, Magna. Plano Nacional de Educação e o regime de colaboração: os indicadores educacionais e financeiros. RBPAE, v. 30, n. 2, p. 417 -433, maio/ago. 2014.

FREITAS, Kátia Siqueira de. Planejamento Educacional: o instrumento na busca da qualidade e da eficácia. GERIR, Salvador, v. 9, n. 34, p. 12-38, 2003.

GAZETA WEB. Pré-escola: Alagoas avançou em 2016. Disponível em: http://gazetaweb.globo.com/ gazetadealagoas/noticia.php?c=310328. Acesso em: 16 nov. 2017.

HORTA, José Silvério Baia. Plano Nacional de Educação: da tecnocracia à participação democrática. In: CURY, Carlos Roberto Jamil et al. Medo à liberdade e compromisso democrático: LDB e Plano Nacional de Educação. São Paulo: Editora do Brasil, 1997.

OBSERVATÓRIO DO PNE. Ensino Médio. Disponível em: http://www.observatoriodopne.org.br/ metas-pne/3-ensino-medio/indicadores. Acesso em: 14 nov. 2017

SAVIANI, Demerval. Sistema Nacional de Educação articulado ao Plano Nacional de Educação.

Revista Brasileira de Educação v. 15 n. 44. p. 308-412, maio/ago. 2010.

SHIROMA, Eneida Oto. Política educacional. Rio de Janeiro: Lamparina, 2011. 
Recebido em: 3 de Dezembro de 2017

Avaliado em: 19 de Abril de 2018

Aceito em: 19 de Abril de 2018

\section{四回

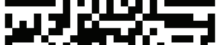

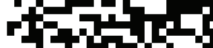

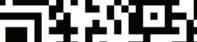

\section{Como citar este artigo:}

ROMEO, Andrea. Lo special account del fenomeno religioso nel dibattito nordamericano. Argumenta Journal Law, Jacarezinho - PR, Brasil, n. 29., 2018, p. 15-48. DOI: 10.17564/2316-3828.2018v7n1p13-24

1 Doutora e Mestre em Educação pela Universidade Federal de Pernambuco - UFPE; Professora do Programa de Pós-Graduação da Universidade Federal de Alagoas UFAL. E-mail: inaldasantos@uol.com.br.

2 Doutoranda e Mestre em Educação pela Universidade Federal de Alagoas - UFAL; Professora do Centro Universitário Mauricio de Nassau - UNINASSAU.

E-mail: jacyufal@gmail.com

\section{(2) (1) ()}

Este artigo é licenciado na modalidade acesso abertosob a Atribuição-Compartilhalgual CC BY-SA

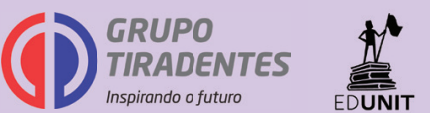

